\title{
Superior mesenteric vein thrombosis and oral contraceptives
}

\author{
M. B. Rose \\ M.A., M.B., F.R.C.S. \\ St Peter's Hospital, Chertsey, Surrey*
}

\section{Summary}

Five cases are reported of superior mesenteric vein thrombosis occurring in women taking oral contraceptives.

The condition is reviewed, and its possible relationship to the drug discussed.

\section{Introduction}

Women taking oral contraceptives have an increased risk of developing deep vein thrombosis and pulmonary embolism (Inman \& Vessey 1968). The incidence of superficial vein thrombosis is increased (Royal College of General Practitioners, 1967), and idiopathic cerebral vein thrombosis may occur in these patients (Atkinson, Fairburn \& Heathfield, 1970). It might ke expected therefore that the visceral venous system would also te liable to thrombosis in patients taking oral contraceptives.

Idiopathic superior mesenteric vein thrombosis is an uncommon but well documented condition (Berry \& Bougas, 1950; Naitove \& Weismann, 1965) that occurs most often in middle-aged or elderly patients. However, four cases have already been reported in young women taking oral contraceptives (Reed \& Coon, 1963; Civetta \& Kolodny, 1970; Hurwitz et al., 1970) and this paper gives an account of another five such cases; one of these has been seen personally and details of the other four have been obtained with the help of the Committee on Safety of Drugs.

\section{Case reports}

\section{Case 1}

A housewife aged 40 was admitted to hospital with a 12-hr history of abdominal pain. She had been unwell for several days; the recent pain was severe, colicky, and associated with vomiting. She had been pregnant eight times, and had taken Gynovlar 21 (ethinyloestradiol $50 \mu \mathrm{g}$, norethisterone acetate $3 \mathrm{mg}$ ) for 5 years. She had also been treated intermittently

\footnotetext{
* Present address: St. Thomas' Hospital, London, S.E.1.
}

with oral iron for anaemia resulting from menorrhagia, but gave no history of other drugs.

On admission she was unwell, with a pulse rate of $120 / \mathrm{min}$ and blood pressure $130 / 80$. The abdomen was distended with generalized tenderness but no rigidity, and bowel sounds were absent. $\mathrm{Hb}, 9 \cdot 1$ $\mathrm{g} / 100 \mathrm{ml}$; WBC, $25,000 / \mathrm{mm}^{3}$; serum amylase, 111 Somogyi units $/ 100 \mathrm{ml}$. Plain radiographs of the $\vec{c}$ abdomen showed free fluid, and fluid levels in the small bowel.

At laparotomy blood-stained free fluid was foung $\vec{\varphi}$ in the peritoneal cavity. Almost the whole small bowe was dark and thick-walled with an oedemato mesentery. The mesenteric veins contained thrombus which extruded on dissection; the arteries pulsated and bled freely. The affected bowel was excised and $\stackrel{0}{\not}$ end-to-end anastomosis performed leaving about $\stackrel{\square}{\complement}$ $2 \frac{1}{2} \mathrm{ft}(75 \mathrm{~cm})$ of small intestine. Histological examina- $\overrightarrow{\vec{O}}$ tion of the specimen confirmed venous thrombosis 3 and infarction with normal arteries. No local cause for the thrombosis was apparent.

Postoperative heparin was given, and the patient's initial progress was satisfactory. On the fourth post- 3 . operative day, when warfarin had been substituted for heparin, she complained of abdominal pain. The abdomen became distended and tender. Heparin was $\mathrm{O}$ recommenced, but her condition deteriorated and $₹$ despite intensive supportive therapy she died 3 days 음 later.

Necropsy. Free blood was found in the peritoneal cavity. The anastomosis had failed to heal, causing $\bar{N}$ peritonitis, and the superior mesenteric vein was solid with thrombus from its smallest tributaries to 0 the portal vein. The splenic vein was similarly throm- $\omega$ bosed, and the portal vein showed partial occlusion. Histological examination showed the oldest throm- 0 bus to be that in the portal vein, where there was $\stackrel{D}{\varnothing}$ peripheral organization with some fresh clot centrally. $\stackrel{?}{+}$ The thrombus in the splenic vein appeared the most $\underset{T}{T}$ recent, and that in the superior mesenteric vein inter- $\frac{\vec{D}}{\Phi}$ mediate. It was considered that the initial thrombosis 
had been in the portal vein, 1-2 weeks earlier, with subsequent distal spread. No cause was found to account for the thrombosis and in particular no neoplasm was present.

\section{Case 2}

A 20-year-old factory worker was admitted to hospital with a history of 3 days' colicky abdominal pain, vomiting and constipation. She had been taking Lyndiol (mestranol $150 \mu \mathrm{g}$, lynoestrenol $5 \mathrm{mg}$ ) for 6 months; the only other drugs that had been prescribed were antibiotics (ampicillin and tetracycline). The blood pressure was 130/80, and abdominal examination elicited generalized tenderness only. She improved with conservative treatment, but 2 days later vomited $150 \mathrm{ml}$ of blood and was taken to the operating theatre.

At operation. The jejunum was found to be gangrenous, but with the main mesenteric arteries pulsating. Dead bowel was resected and end-to-end anastomosis performed. Paralytic ileus persisted after operation and she died 6 days later with a clinical diagnosis of peritonitis.

Necropsy showed thrombosis of the superior and inferior mesenteric veins and the splenic vein. Thrombus was also found in the deep veins of the leg, and pulmonary emboli were present in the lungs. The mesenteric arteries were patent.

\section{Case 3}

A 33-year-old woman had been taking Anovlar (ethinyl oestradiol $50 \mu \mathrm{g}$, norethisterone acetate $4 \mathrm{mg}$ ) for 9 months. She was admitted to hospital with a 5-day history of abdominal pain and vomiting. Besides oral contraceptives she had been taking salicylates for backache, and potassium perchlorate for control of thyrotoxicosis. The pulse rate was 100 and the blood pressure 130/80; examination of the abdomen elicited right-sided tenderness, which later shifted to the left. The WBC was $6500 \mathrm{~mm}^{3}$. She was treated conservatively but the pain persisted. On the second day after admission she collapsed, and responded to the transfusion of plasma and blood, but the following day collapsed again with a large haematemesis and died.

Necropsy showed thrombus occluding the superior mesenteric, portal and splenic veins with massive small bowel infarction. The main arteries were normal.

\section{Case 4}

This 42-year-old woman had a past history of puerperal pulmonary emboli and had been on Lyndiol 2.5 (mestranol $75 \mu$ g lynestrenol $2.5 \mathrm{mg}$ ) for 4 months. She complained of upper abdominal pain for 10 days, becoming severe and associated with vomiting on the day of admission.
Examination revealed a blood pressure of $130 / 80$, and there was upper abdominal tenderness and guarding. The WBC was $10,100 / \mathrm{mm}^{3}$.

Laparotomy revealed a 3 -in $(7.5 \mathrm{~cm})$ segment of gangrenous small intestine caused by local superior mesenteric vein thrombosis. The affected segment was resected and after operation warfarin was given. She made a slow but complete recovery.

\section{Case 5}

A woman aged 32 presented with a 2-week history of colicky abdominal pain radiating to the back, with associated vomiting. During this time abdominal examination had revealed no abnormal physical signs.

On admission the pain was more severe, and abdominal distension and tenderness were present. The pulse rate was $140 / \mathrm{min}$. She had been taking Orthonovin (mestranol $100 \mu \mathrm{g}$, norethisterone $2 \mathrm{mg}$.) for 18 months. Investigations showed the WBC to be $23,000 / \mathrm{mm}^{3}$.

At laparotomy the same day a $3-\mathrm{ft}(90 \mathrm{~cm})$ length of ileum was found to be gangrenous, with thrombosis of the adjacent mesenteric veins. No cause was apparent and the mesenteric arteries appeared normal. The affected segment of intestine was resected; histological examination of this confirmed venous infarction. Low molecular weight dextran was given intravenously daily after operation, but the patient made poor progress and $\mathbf{8}$ days later a further operation was carried out because of signs of peritonitis. A further $3 \mathrm{ft}(90 \mathrm{~cm})$ of ileum distal to the previous anastomosis was gangrenous and required resection. Heparin was given after this operation, and the patient eventually made a full recovery.

\section{Discussion}

Superior mesenteric vein thrombosis may be caused by local factors such as trauma, infection, or venous obstruction, or may be associated with hypercoagulable states such as polycythaemia rubra vera and carcinomatosis. The condition was first distinguished from mesenteric arterial obstruction in 1935 (Warren \& Eberhard, 1935) and these authors noted a number of cases where no cause, local or general, could be found. This 'idiopathic' superior mesenteric vein thrombosis has since been discussed in detail (Naitove \& Weismann, 1965, Trinkle et al., 1969). Its relationship to portal vein thrombosis is unclear, and it has been suggested both that portal vein thrombosis may spread distally to involve the mesenteric veins (Thompson \& Sherlock 1964), and also that segmental mesenteric vein thrombosis may spread proximally to involve the portal vein (Mavor, 1966).

Idiopathic superior mesenteric vein thrombosis occurs in all age groups but is most common in the middle-aged and elderly. Men are more often 
affected than women. A past history of venous thrombosis occurring elsewhere in the body is common (Naitove \& Weismann, 1965; North \& Wollenman, 1952) and in forty-three cases collected from the literature such a history is recorded in fifteen $(35 \%)$. Prodromal symptoms, usually abdominal pain, are common, and the patient presents with symptoms and signs of intestinal obstruction, while late cases have signs of peritonitis. Abdominal physical signs are usually limited to distension and tenderness, and are less than might be expected from the distress of the patient. There are no diagnostic laboratory investigations, but the white cell count is usually raised (often over $20,000 / \mathrm{mm}^{3}$ ), and peritoneal aspiration may reveal serosanguinous fluid with a normal amylase content. At operation a variable length of small intestine is found to be discoloured and oedematous with a thickened mesentery which hides pulsating arteries. The mesenteric veins extrude clot when incised.

Treatment is surgical, with wide resection of affected bowel, and the postoperative administration of anticoagulants. The use of anticoagulants is supported by an analysis of forty-three cases reported since 1950 (Table 1). It is of interest to note that of the twenty-five patients who survived after operation, in seven there was a recurrence of superior mesenteric vein thrombosis, but in no case did this occur during treatment with anticoagulants. Late recurrence of superior mesenteric vein thrombosis is known to occur, so that long-term anticoagulant therapy is desirable. The prognosis of the disease is good provided operation is undertaken early enough.

Four cases have been recorded of superior mesenteric vein thrombosis occurring in women taking oral contraceptives (Reed \& Coon, 1963; Civetta \& Kolodny, 1970; Hurwitz et al., 1970), and five more are here reported. The disease is similar in presentation and clinical course to the 'idiopathic' form, apart from occurring in younger women. The mortality in these cases has been high $(56 \%)$ and apparently not affected by the use of anticoagulants, although the numbers are small (Table 2). In six cases the contraceptive pill taken was known, and three were of the 'high oestrogen' type containing $100 \mu \mathrm{g}$ or more of oestrogen preparation. This type

TABLE 1. Outcome of treatment in superior mesenteric vein thrombosis in forty-three cases reported since 1950

\begin{tabular}{lccc}
\hline \multicolumn{1}{c}{ Treatment } & Survived & Died & Total \\
\hline Bowel resection, no anticoagulants & 10 & $9^{*}$ & 19 \\
Bowel resection plus anticoagulants & 15 & 0 & 15 \\
$\begin{array}{l}\text { No bowel resection, no anti- } \\
\text { coagulants }\end{array}$ & 0 & 9 & 9 \\
& & & 43 \\
\hline
\end{tabular}

* Seven of these cases showed necropsy evidence of postoperative extension of thrombosis
TABLE 2. Outcome of treatment in superior mesenteric vein thrombosis in nine cases occurring in women taking oral contraceptives

\begin{tabular}{lccc}
\hline Treatment & Survived & Died & Total \\
\hline Bowel resection, no anticoagulants & 3 & $3^{*}$ & 6 \\
Bowel resection plus anticoagulants & 1 & 1 & 2 \\
$\begin{array}{l}\text { No bowel resection, no anti- } \\
\text { coagulants }\end{array}$ & 0 & 1 & 1 \\
& & & 9 \\
\hline
\end{tabular}

* Two of these cases showed necropsy evidence of postoperative extension of thrombosis

of oral contraceptive is known to be associated with a greater risk of deep vein thrombosis (Inman et al., $\vec{\omega}$ 1970).

It has been pointed out by Doll \& Vessey (1970) that the evaluation of rare side-effects of oral contraceptives is difficult. It requires either prospective trials or large scale retrospective studies. Case or reports alone, as presented here, cannot prove a $\vec{s}$ causal relationship. It is of interest that other vis- $\hat{O}_{0}$ ceral thromboses have been reported in association $\circ$ with oral contraceptives, for example hepatic vein thrombosis (British Medical Journal, 1971) and $\bar{c}$ superior mesenteric or coeliac artery thrombosis (Brennan Clarke \& Macbeth, 1968; Welin \& Persson, $\overrightarrow{0}$ 1968). Ischaemic colitis has also been described if such patients (Kilpatrick et al., 1968; Ward \& Stevenson, 1968; Hurwitz et al., 1970; Cotton \& Legi Thomas, 1971) but the aetiology of this condition is uncertain. All these conditions are rare, and comparison of the incidence in patients taking oral contraceptives with others is difficult.

At present therefore, it is impossible to prove a $\overrightarrow{\overrightarrow{0}}$ causal relationship between oral contraceptives and superior mesenteric vein thrombosis. It is suggested, however, that an accurate record of all drugs taken by a patient is essential, and that the possibility of a visceral venous thrombosis should be considered in any woman who presents with abdominal pain while taking oral contraceptives.

\section{Acknowledgments}

These cases could not have been brought together without the Committee on Safety on Drugs, and I am most grateful to to Dr K. Lovel for his work in collecting them. I am most grateful to $\mathrm{Mr}$ A. Eley for permission to publish the first case, $N$ and to the other surgeons concerned for permission to report details of their patients, viz. Mr Ewan Cameron of Alexandria $\mathrm{O}$ Hospital, Dunbartonshire, Mr K. G. Orr of Mid Ulster N Hospital, Magherafelt (previously published: Lowry, Orr \& $\omega$ Wade, 1969), Mr P. W. Seargeant of Kings Lynn Hospital, Norfolk, and Mr N. E. Winstone of Selly Oak Hospital, Birmingham.

My thanks are also due to Mr C. J. Anders and Mr B. T. Jackson for considerable help and advice, to Dr C. F. Ross for assistance with interpretation of the pathology in Case $1, \vec{D}$ and to Anne Hales and Hilary Rose for their time and $\stackrel{\vec{D}}{\circ}$ patience. 


\section{References}

Atkinson, E.A., Fairburn, B. \& Heathfield, K.W.G. (1970) Intracranial venous thrombosis as a complication of oral contraception. Lancet, ii, 914.

Berry, F.B. \& Bougas, J.A. (1950) Agnogenic venous mesenteric thrombosis. Annals of Surgery, 32, 450.

Brennan, M.F., Clark, A.M. \& Macbeth, W.A. (1968) Infarction of the mid gut associated with the use of oral contraceptives. New England Journal of Medicine, 279, 1213.

British Medical Journal (1971) Hepatic vein occlusion. 3, 550.

CivetTa, J.M. \& Kolodny M. (1970) Mesenteric venous thrombosis associated with oral contraceptives. Gastroenterology, 58, 713.

Cotton, P.B. \& Lea Thomas, M. (1971) Ischaemic colit is and the contraceptive pill. British Medical Journal, 2, 27.

Doll, R. \& VeSSEY, M.P. (1970) Evaluation of rare adverse effects of systemic contraceptives. British Medical Journal, $1,33$.

Hurwitz, R.L., Martin, A.J., Grossman, B.E. \& Waddell, W.R. (1970) Oral contraceptives and gastro intestinal disorders. Annals of Surgery, 172, 892.

INMAN, W.H.W. \& VESSEY, M.P. (1968) Investigation of deaths from pulmonary, coronary and cerebral thrombosis and embolism. British Medical Journal, 2, 193.

InMan, W.H.W., Vessey, M.P., Westerholm, B. \& EngelUND, A. (1970) Thrombo-embolic disease and the steroidal content of oral contraceptives. British Medical Journal, 2, 203.

Kilpatrick, Z.M., Silverman, J.F., Betancourt, F. FARMAN, J. \& LAWSON, J.P. (1968) Vascular occlusion of the colon and oral contraceptives. New England Journal of Medicine, 278, 438.
LOWRY J.B., ORR, K.G. \& WADE, W.G. (1969) Infarction of the small intestine associated with oral contraceptives. Journal of the Irish Medical Association, 62, 260.

Mavor, G.E. (1966) Mesenteric vascular occlusion. In: Clinical Surgery (Ed. by C. Rob, R. Smith \& C. Naunton Morgan), Vol. 10, p. 503. Butterworths, London.

Naitove, A. \& Weismann, R.E. (1965) Primary mesenteric venous thrombosis. Annals of Surgery, 161, 516.

NorTh, J.P. \& Wollenman, O.J. (1952) Venous mesenteric occlusion in the course of migrating thrombo-phlebitis. Surgery Gynaecology and Obstetrics, 95, 665.

REeD, D.L. \& Coon, W.W. (1963) Thrombo-embolism in patients receiving progestational drugs. New England Journal of Medicine, 269, 622.

Royal College of General Practitioners (1967) Oral contraception and thrombo-embolic disease. Journal of the Royal College of General Practitioners, 13, 267.

Thompson, E.N. \& Sherlock, S. (1964) The aetiology of portal vein thrombosis. Quarterly Journal of Medicine, 33, 465.

Trinkle, J.K., Rush, B.F., Fullmer, M.A., Bryant, L.R. \& RAMS, J. (1969) The operative management of idiopathic mesenteric venous thrombosis with intestinal infarction. American Surgeon, 35, 338.

WARD, G.W. \& STEVENSON, J.R. (1968) Colonic disorders and oral contraceptives. New England Journal of Medicine, 278, 910.

WARren, S. \& Eberhard, T.P. (1935) Mesenteric venous thrombosis. Surgery Gynaecology and Obstetrics, 61, 102.

Welin, G. \& Persson, T. (1968) Oral contraceptives and thrombosis of the coeliac artery. Lancet, ii, 1345. 